\title{
Nutrient and Chlorophyll $\alpha$ Variability at a Micro-Scale Level in a Suspended Mussel Culture
}

\author{
Amalia Moriki, Dimitris Petridis, Chrysi Papadimitriou, Irene Fantidou, Nikos Kapageridis \\ Department of Food Technology, Alexander Technological Educational Institute of Thessaloniki (ATEITh), Sindos, Thessaloniki, \\ Greece \\ Email:moriki@aqua.teithe.gr
}

How to cite this paper: Moriki, A., Petridis, D., Papadimitriou, C., Fantidou, I. and Kapageridis, N. (2017) Nutrient and Chlorophyll $\alpha$ Variability at a Micro-Scale Level in a Suspended Mussel Culture. Journal of Water Resource and Protection, 9, 1491-1509.

https://doi.org/10.4236/jwarp.2017.912095

Received: October 20, 2017

Accepted: November 26, 2017

Published: November 29, 2017

Copyright $\odot 2017$ by authors and Scientific Research Publishing Inc. This work is licensed under the Creative Commons Attribution International License (CC BY 4.0).

http://creativecommons.org/licenses/by/4.0/

(c) $\underset{\mathrm{EY}}{\mathrm{C}}$ Open Access

\begin{abstract}
Mussel farming by the long-line system, in the shallow waters of the NW Thessaloniki Gulf, Greece, is a vital economic activity for the local communities. The management practices play an important role both in the environmental quality and the support of the healthy growth of mussels. An experimental line of mussels in suspension placed at different sock distances as a management practice was systematically monitored for nutrients, chlorophyll $\alpha$ and dissolved oxygen. The study at four different mussel densities (distances of the socks) lasted from July 2014 to April 2015, covering the growth, reproduction and harvest cycle of mussels. Additional sampling took place in two selected sock distances, 30 and $70 \mathrm{~cm}$, in the second sampling period, May-August 2015. The variability of nutrients along with chlorophyll $\alpha$ and dissolved oxygen, seasonally, spatially and vertically, was examined with the application of multivariate statistical analysis. The results showed low variation of nitrates among the sites but statistically significant differences of dissolved oxygen, ammonium, phosphate and chlorophyll $\alpha$. The application of environmental indicators (TRIX, EI) in the data set was a useful tool in the identification of different variation schemes of the measured parameters in the cultures of various mussel densities.
\end{abstract}

\section{Keywords}

Nutrients, Chlorophyll $\alpha$, Mussel Farming, Thessaloniki Gulf, Eutrophication Indicators

\section{Introduction}

Coastal waters are fragile ecosystems receiving environmental pressures from 
human activities. Mussel farming is one of these activities that contributes to the human pressures and potentially changes the natural environment. The Gulf of Thessaloniki (NW Aegean Sea) is a shallow coastal area influenced by municipal and industrial actions and effluents, shipping, fishing, as well as estuarine inputs from four major rivers. Mussel cultures both by long line and pole systems are located in the area and comprise an important economic activity [1].

Primary production and assimilation of phytoplankton and detritus as food for mussel growth, through the filtration of water, are the key factors affecting the ecological environment of a mussel farm [2]. The metabolic activity of mussels increases detritus and organic by-products as feces and pseudo feces [3] while nutrients such as ammonium and phosphate are released by the bivalves [4]. The enrichment of the water column in ammonium, phosphate and silicate is also possible due to biodegradation or biodeposition to the bottom [5]. $\mathrm{Nu}$ trient cycling is also affected by feces and pseudo feces biodegradation in the water column that deliberates inorganic nutrients [6]. In this way, high density of bivalves in mussel cultures can affect nutrient dynamics in the coastal environment.

The development of indicators of nutrient impacts and eutrophication in coastal waters has received considerable effort [7] [8] [9]. The classification process is based on three major issues: nutrient enrichment, primary production and undesirable effects expressed as dissolved oxygen depletion [10].

However, mussel farming differs from fish farming concerning the trophic enrichment of coastal waters. Mussels both produce and consume nutrients through filtering of water [4] thus being able of mitigating nutrients and resulting eutrophication in coastal areas. Sediment organic matter enrichment, underneath the mussel culture, though, activates higher nutrient regeneration rates [5] [11] increasing nutrient concentration in the deeper layer of the water column. The identification of potential impacts of dense aggregations of mussels on the trophic status of the coastal waters that host the activity of mussel farming has two aspects: 1) the support of the growth of mussels and 2) the prevention of undesirable effects on the water column and the quality of mussels.

The seasonal nutrient variation in a long-line of a mussel farm in the area of Chalastra (NW Thessaloniki Gulf) was investigated in this work, during the reproduction, growth and harvest cycle of mussels, in twelve samplings from July 2014 to April 2015. Sampling of water took place in four sites of the long-line, with various densities of cultured mussels and in a reference station, outside the culture. Additional samples were collected monthly in the period May-August 2015, in two sites of different mussel density. The results are depicting the variation of nutrients in the culture's micro-environment in an attempt to identify different impacts of the culture's density in the trophic status of the coastal waters of Thessaloniki's Gulf. Multivariate statistical analysis and eutrophication indicators [9] [10] were used as tools for the identification of the variation schemes of nutrients, chlorophyll $\alpha$ and dissolved oxygen in the cultures of dif- 
ferent mussel density.

\section{Materials and Methods}

Seawater samples were collected by a van Dorn water sampler, from three depths, $1 \mathrm{~m}, 5 \mathrm{~m}$ and at the bottom layer, close to $10 \mathrm{~m}$, from a long-line in a mussel culture (Figure 1) at sites of different mussel density (Figure 2). The densities were determined by the distance among the suspended mussel socks. Four sampling sites were selected at $30 \mathrm{~cm}, 50 \mathrm{~cm}, 70 \mathrm{~cm}$ and $90 \mathrm{~cm}$ distance (Figure 2). Samples were also collected from a reference site, outside the farm at a distance of $2.5 \mathrm{~km}$ (Figure 1). Seawater samples were filtered on-board through membrane $0.45 \mu \mathrm{m}$ filters [12] and kept in $-18^{\circ} \mathrm{C}$ until their analysis. Nitrate, nitrite, phosphate and silicate values were measured spectrophotometrically [13]. Dissolved oxygen was measured by the Winkler method on board [14], while chlorophyll $\alpha$ was determined after the extraction with acetone on a double beam spectrophotometer [13]. Analysis of ammonium was performed by

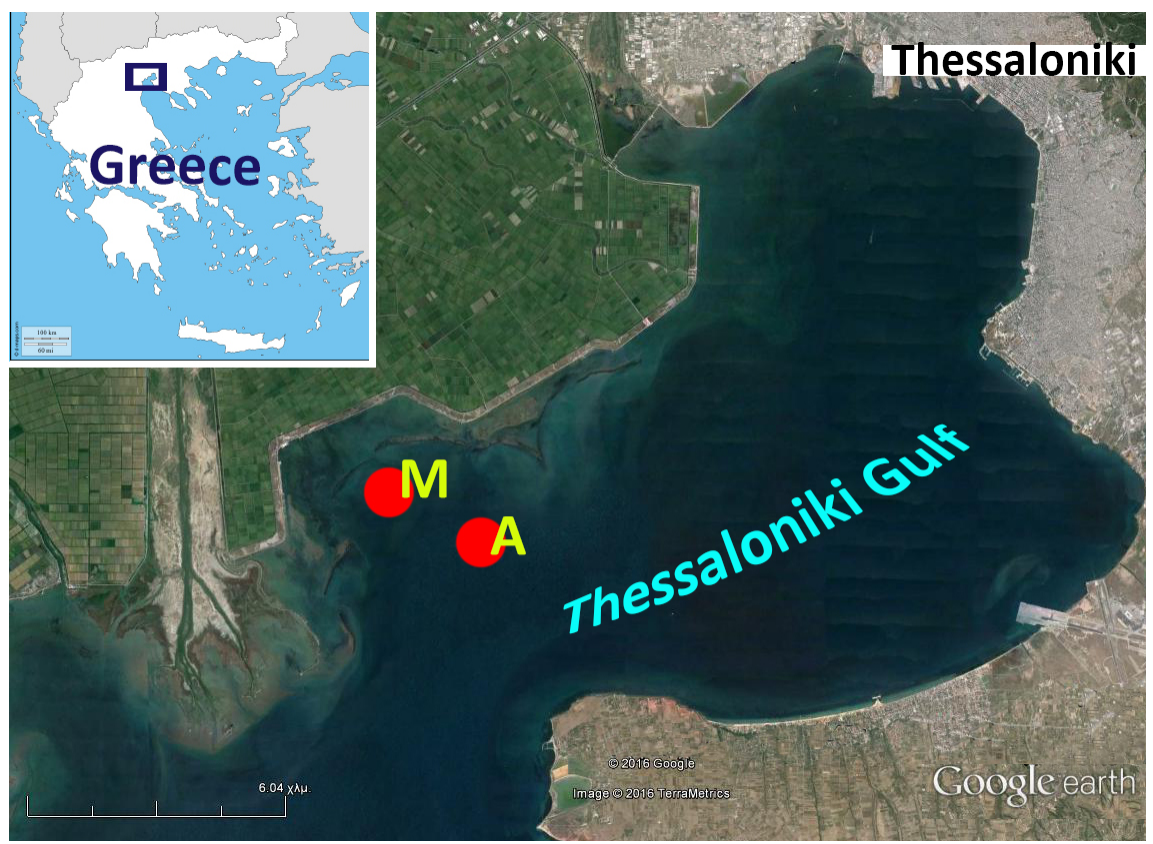

Figure 1. Map with the location of the experimental long-line of mussels ( $M$ ) and the reference station (A) at a distance of $2.5 \mathrm{~km}$ southeast (adapted from google earth).

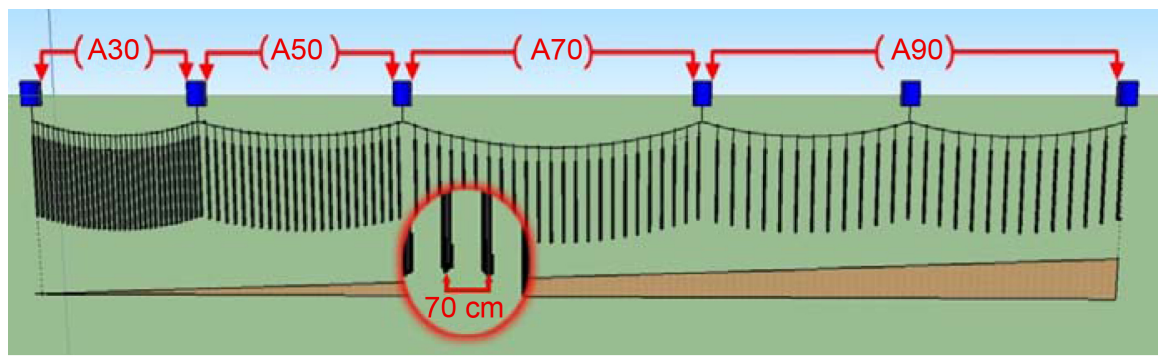

Figure 2. Layout of the production line with the different distances between the suspended mussel socks and their vicinity to the bottom. 
the phenolhypochlorite method [15].

Data were treated using a three factor analysis of variance (seasonality, water depth and distance between socks) on the measured parameters (nutrients, chlorophyll $\alpha$ and dissolved oxygen) inside the long line mussel culture. Statistical differences between factor levels were further examined in the graphs of the parameters correlations and sample scores produced by the Principal Component Analysis (PCA) which was applied on the whole data set of the study.

\section{Water Quality Indices}

TRIX is an eutrophication index [10] for the evaluation of trophic levels in coastal waters. It is a linear combination of the logarithm of four variables, chlorophyll $\alpha$, total inorganic nitrogen, inorganic phosphorus and the absolute percentage of the deviation from the dissolved oxygen saturation.

$$
\text { TRIX }=\left[\log _{10}\left(\mathrm{CPO}_{4} * \mathrm{CDIN} * \mathrm{CChl} \alpha * \mathrm{D}_{0} \mathrm{O}_{2}\right)+1.5\right] / 1.2
$$

CDIN is the concentration of total dissolved inorganic nitrogen $\left(\mathrm{NO}_{3}+\mathrm{NO}_{2}+\right.$ $\mathrm{NH}_{4}$ ) and $\mathrm{D} \% \mathrm{O}_{2}$ is the absolute percentage of the deviation from the dissolved oxygen saturation. This index was first applied to describe eutrophication status of Italian coastal waters (Adriatic Sea) but has been used in other coastal areas as well [8].

EI eutrophication index derived from the application of principal component analysis (PCA) on a nutrient and chlorophyll $\alpha$ values data set from Greek oligotrophic waters [9] and is suggested as follows:

$\mathrm{EI}=0.279 \mathrm{CPO}_{4}+0.261 \mathrm{CNO}_{3}+0.296 \mathrm{CNO}_{2}+0.275 \mathrm{CNH}_{3}+0.214 \mathrm{Chl} \alpha$

\section{Results}

The variation of phosphates in the period July 2014 to April 2015, in the depths 1,5 and $10 \mathrm{~m}$, in the reference station and the four different handlings, is presented in Figure 3. The concentration of phosphates ranged from 0.01 to 0.58 $\mu \mathrm{M}$ (Table 1). The highest concentrations were measured at the depth of $5 \mathrm{~m}$, where the mussels are suspended. All nutrients showed expectedly great seasonal variability in concentration (Table 2). Phosphates were more sensitive during the sampling period, distance of mussels and deep waters (Table 2).

Nitrate values were similar in the reference station and among the handlings (Figure 4), with a concentration range $0.02-8.61 \mu \mathrm{M}$ (Table 1). Higher concentrations were presented in November and in the end of winter and spring months (Figure 4). Nitrite values ranged from 0.01 to $2.02 \mu \mathrm{M}$, with a mean value of $0.35 \mu \mathrm{M}$ and were high in October and November as well as in the spring months (Figure 5).

The concentration of ammonium presented statistically important differences between the sampling sites (Table 2). Ammonium values ranged from 0.01 to $42.11 \mu \mathrm{M}$ (Figure 6). The higher concentrations were observed in October and November, in the spring months and in the summer, in the bottom layer. 

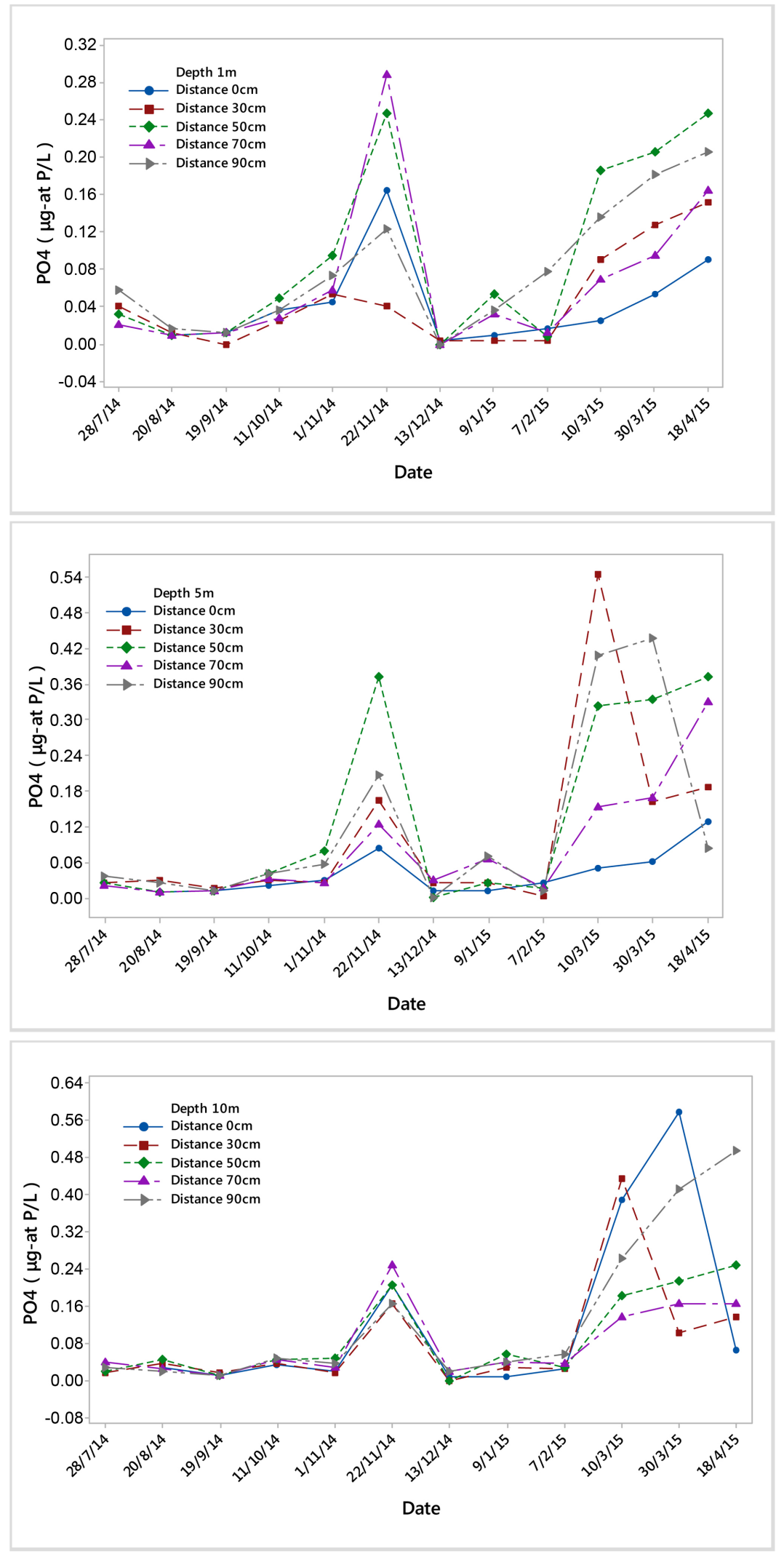

Figure 3. Variation of phosphates during the sampling period July 2014-April 2015 , in the depths 1,5 and $10 \mathrm{~m}$ in the four sites of different distance between the mussel socks and the reference station (distance "0"). 

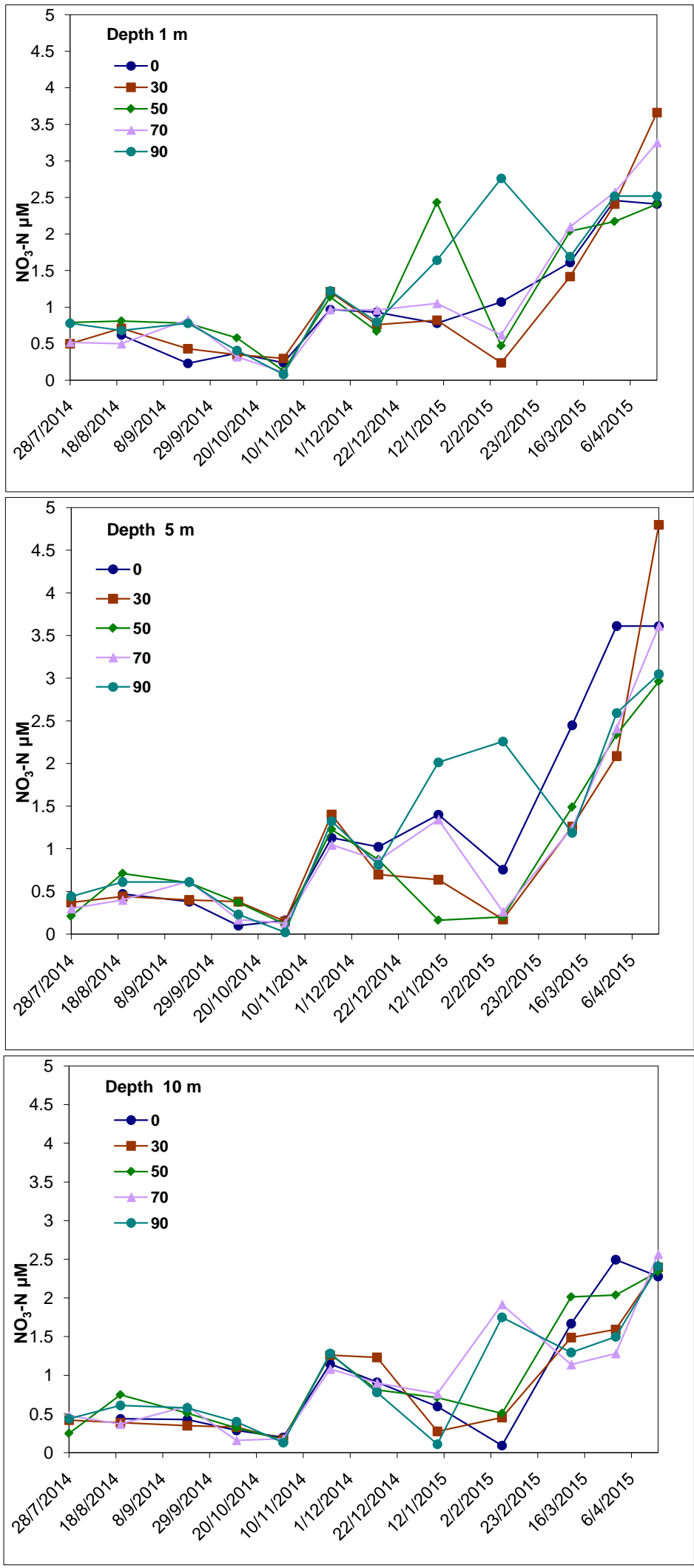

Figure 4. Variation of nitrates during the sampling period July 2014-April 2015, in the depths 1,5 and $10 \mathrm{~m}$ in the four sites of different distance between the mussel socks and the reference station (distance " 0 "). 


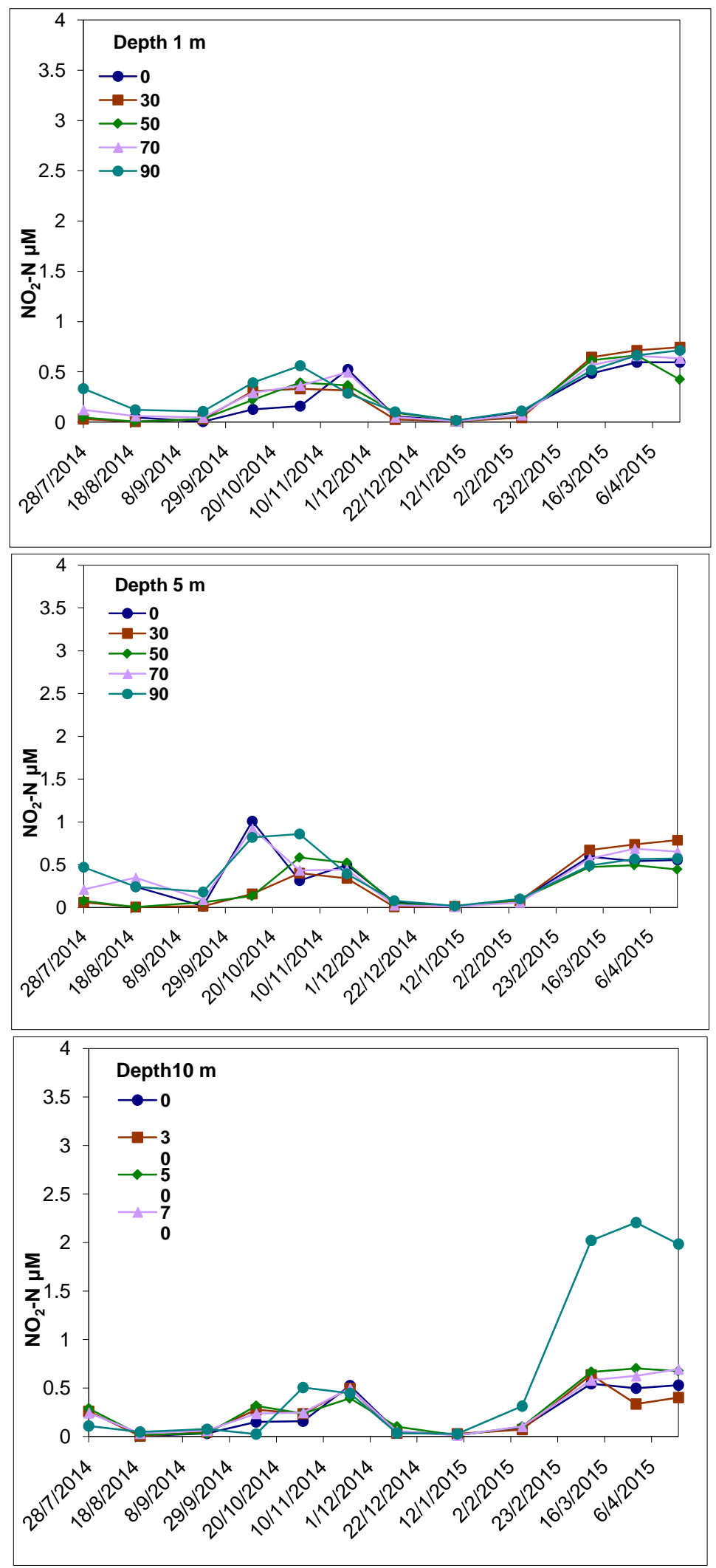

Figure 5. Variation of nitrites during the sampling period July 2014-April 2015 , in the depths 1,5 and $10 \mathrm{~m}$ in the four sites of different distance between the mussel socks and the reference station (distance " 0 "). 


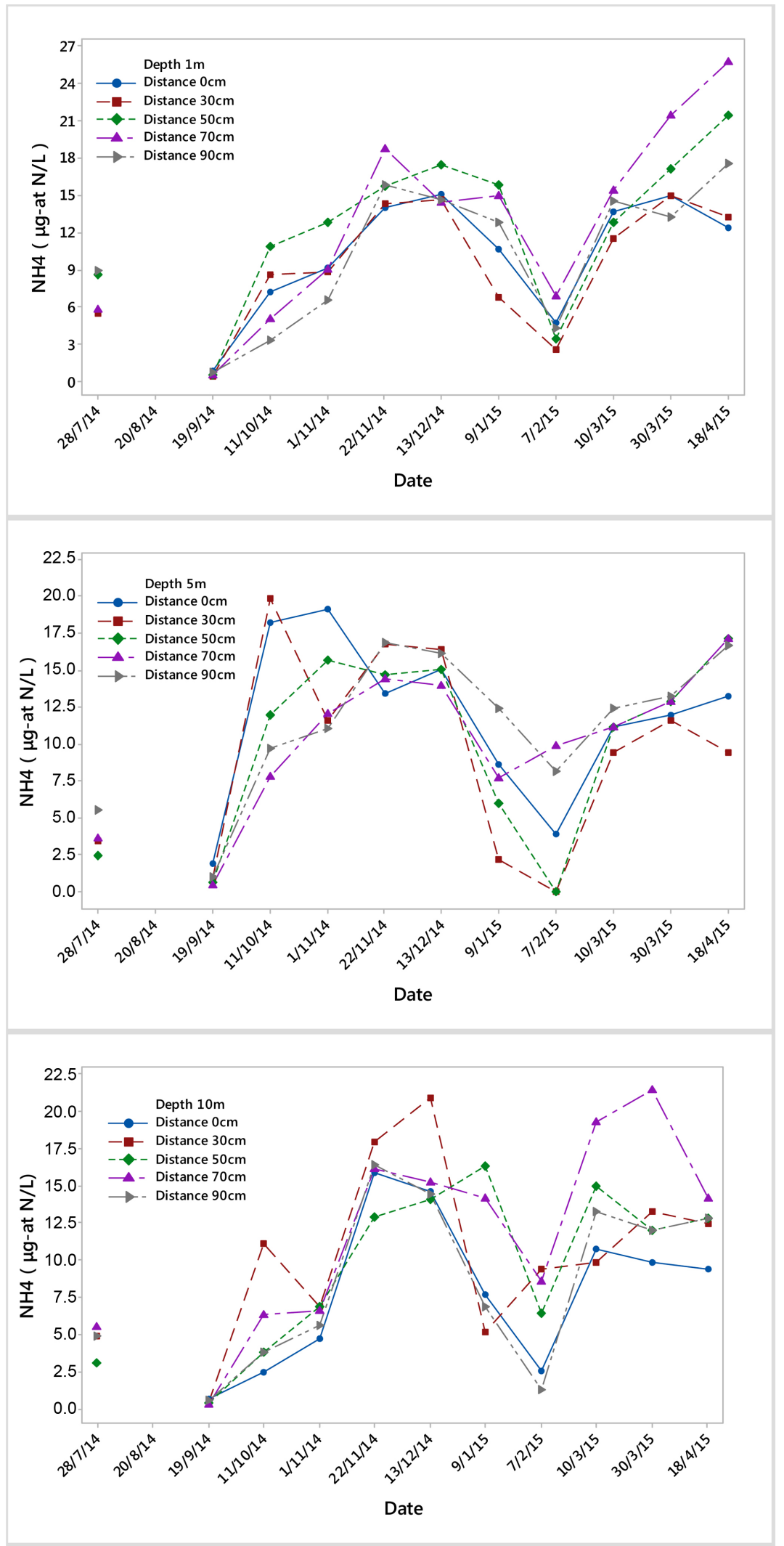

Figure 6. Variation of ammonium during the sampling period July 2014-April 2015, in the depths 1,5 and $10 \mathrm{~m}$ in the four sites of different distance between the mussel socks and the reference station (distance " 0 "). 
Table 1. Mean and range of values of nutrients and chlorophyll $\alpha$, from July 2014 to August 2015 in the sampling sites (cultures of different mussel density and reference site).

\begin{tabular}{ccccccc}
\hline & $\begin{array}{c}\mathrm{PO}_{4}-\mathrm{P} \\
\mu \mathrm{M}\end{array}$ & $\begin{array}{c}\mathrm{NO}_{3}-\mathrm{N} \\
\mu \mathrm{M}\end{array}$ & $\begin{array}{c}\mathrm{NO}_{2}-\mathrm{N} \\
\mu \mathrm{M}\end{array}$ & $\begin{array}{c}\mathrm{NH}_{4}-\mathrm{N} \\
\mu \mathrm{M}\end{array}$ & $\begin{array}{c}\mathrm{SiO}_{4}-\mathrm{Si} \\
\mu \mathrm{M}\end{array}$ & $\mathrm{Chl} \alpha\left(\mathrm{mg} / \mathrm{m}^{3}\right)$ \\
\hline July 2014-April 2015 & & & & & & \\
Mean & 0.09 & 1.10 & 0.31 & 10.47 & 33.61 & 0.56 \\
Minimum & 0.01 & 0.02 & 0.01 & 0.01 & 0.28 & 0.01 \\
Maximum & 0.58 & 4.80 & 2.02 & 25.75 & 82.76 & 12.23 \\
July 2014-August 2015 & & & & & & \\
$\quad$ Mean & 0.08 & 1.29 & 0.32 & 9.62 & 31.56 & 0.52 \\
Minimum & 0.01 & 0.02 & 0.01 & 0.01 & 0.28 & 0.01 \\
Maximum & 0.58 & 8.61 & 2.02 & 42.11 & 82.76 & 12.23 \\
\hline
\end{tabular}

Table 2. Statistically significant effects (in bold) of seasonal and vertical variation (depth) and sock distance on dissolved oxygen, nutrients and chlorophyll $\alpha$, at 0.5 probability reference level.

\begin{tabular}{cccccccc}
\hline Impact & $\mathrm{DF}$ & $\log \mathrm{DO}$ & $\operatorname{logPO}_{4}$ & $\operatorname{logNO}_{3}$ & $\operatorname{logNH}_{4}$ & $\operatorname{logSiO} \mathrm{S}_{4}$ & $\log (\mathrm{Chl} \alpha)$ \\
\hline Date & 10 & $<0.001$ & $<0.001$ & $<0.001$ & $<0.001$ & $<0.001$ & $<0.001011$ \\
Distance & 4 & $<0.001$ & $<0.001$ & 0.858 & 0.326 & 0.425 & $\mathbf{0 . 0 0 1}$ \\
Depth & 2 & $<0.001$ & $\mathbf{0 . 0 0 8}$ & 0.052 & $\mathbf{0 . 0 1 4}$ & 0.329 & 0.800 \\
Error & 127 & & & & & & \\
Total & 143 & & & & & & \\
Observations & & & & & & & \\
\hline
\end{tabular}

Silicates ranged from $0.28-82.76 \mu \mathrm{M}$ (Table 1) and presented low variation among the handlings and the reference station (Figure 7).

Differences in chlorophyll $a$ values were observed in the depths of 5 and $10 \mathrm{~m}$ (Figure 8), showing a reduction of about forty per cent during the spring bloom in the handlings compared to the reference site.

Nutrients, dissolved oxygen and chlorophyll $\alpha$ values were used for the calculation of eutrophication indices, TRIX and EI [9] [10]. The environmental quality status was classified in five ranges: high, good, moderate, poor and bad, corresponding to a quality score from 1 to 5 , respectively.

Table 3 presents the correlation coefficients between nutrients, dissolved oxygen and chlorophyll $a$ values and PCA axes 1 and 2. The first two PCA axes explain $59.8 \%$ of the total variation of the whole data set. Phosphate and N/P show the highest correlation coefficients and therefore are the most important variables for the formation of axes 1 and 2 correspondingly. The variables total $\mathrm{N}$ and ammonium, share equal contribution for the formation of both axes. All the variables under study are shown in Figure 9, forming different directions that easily can be grouped into two bundles of variables. Phosphate with chlorophyll $\alpha$ form the first bundle together with nitrate and nitrite, indicating a positive correlation between higher primary productivity and nutrients. The 


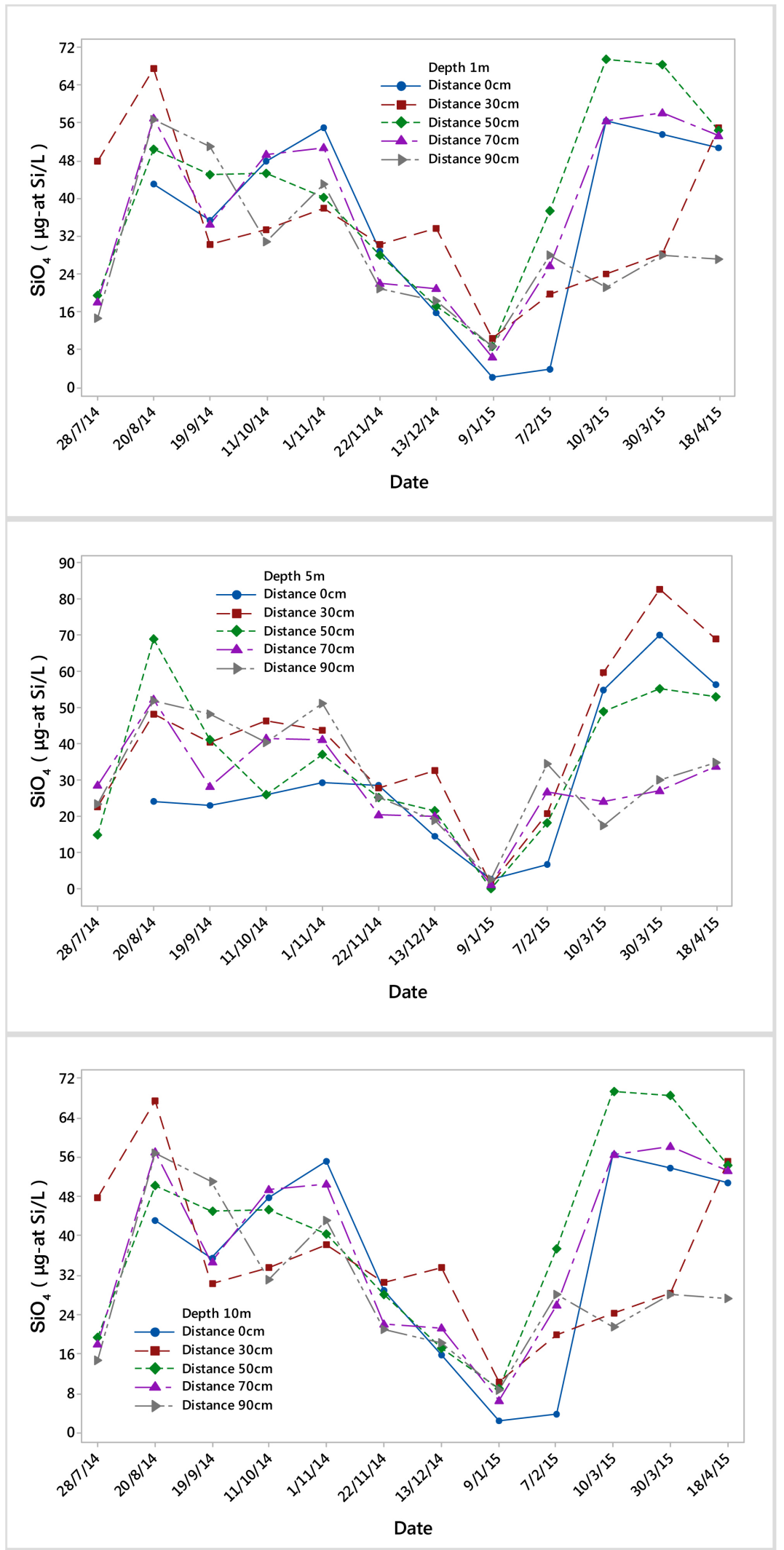

Figure 7. Variation of silicates during the sampling period July 2014-April 2015, in the depths 1,5 and $10 \mathrm{~m}$ in the four sites of different distance between the mussel socks and the reference station (distance "0"). 

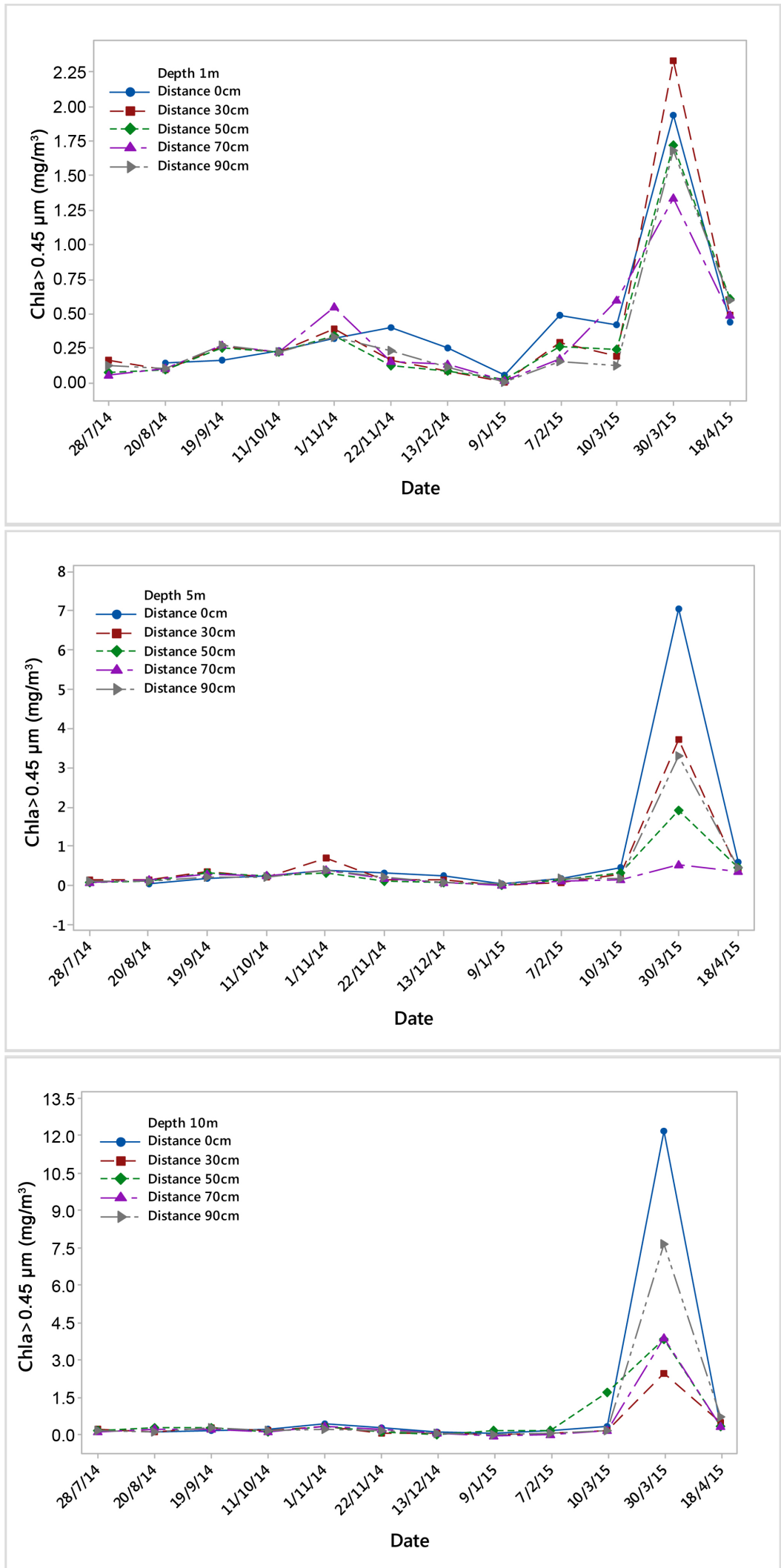

Figure 8. Variation of chlorophyll $\alpha$ values during the sampling period July 2014-April 2015, in the depths 1, 5 and $10 \mathrm{~m}$ in the four sites of different distance between the mussel socks and the reference station (distance "0"). 


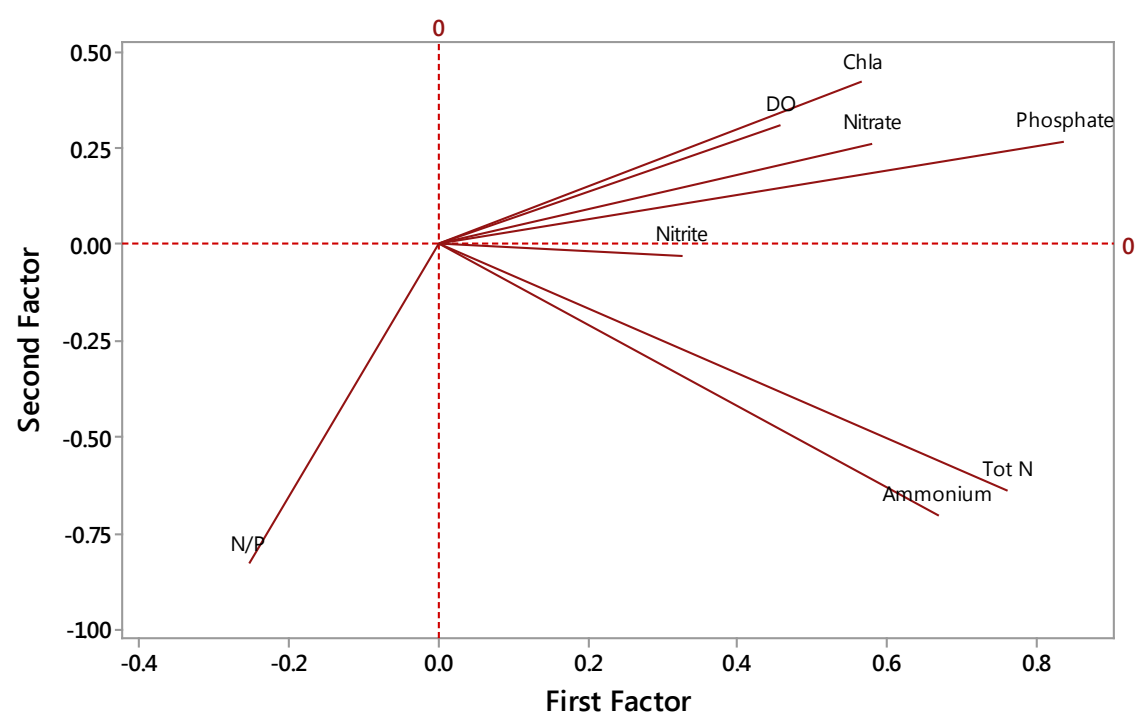

Figure 9. PCA biplot of variable correlation with principal axes. Longer arrows indicate higher correlation values, while acute angles indicate positive correlation and obtuse negative ones, between each pair of variables.

Table 3. Correlation coefficients between the physicochemical variables and PCA axes 1 and 2 and percentage variance determination.

\begin{tabular}{cccc}
\hline Variable & Factor 1 & Factor 2 & Communality \\
\hline Phosphate & 0.838 & 0.268 & 0.774 \\
Total dissolved inorganic Nitrogen & $\mathbf{0 . 7 6 2}$ & -0.640 & 0.991 \\
Ratio N/P & -0.255 & -0.833 & 0.759 \\
Ammonium & $\mathbf{0 . 6 6 8}$ & -0.706 & 0.945 \\
Chlorophyll $\alpha$ & 0.567 & 0.420 & 0.498 \\
Dissolved Oxygen & 0.457 & 0.310 & 0.305 \\
Nitrate & 0.579 & 0.263 & 0.405 \\
Nitrite & 0.326 & -0.030 & 0.107 \\
Variance & 2.7658 & 2.0177 & 4.7835 \\
$\%$ & 34.6 & 25.2 & 59.8 \\
\hline
\end{tabular}

second bundle is formed by ammonium and total nitrogen, characterized by high production rates of ammonium. The ratio N:P is negatively correlated with the first bundle of variables, indicative of an irregular seasonal, spatial and vertical variation of the Redfield ratio at the culture's micro-environment.

In Figure 10, the PCA ordination plot of the variable sample scores, showing the distances between the socks in both sampling periods (July 2014-August 2015) is presented. If we superimpose the Figure 8 and Figure 9, a useful relationship between variables and sample sites reveals. Sites close to particular nutrients show a mutual effect leading to a positive relation: sites with high concentrations of the corresponding nutrients. Marked as " 10 " is the reference station and as "100" the dense culture of $30 \mathrm{~cm}$ distance. There is a clear distinction of the dense culture (bottom right part) and the less dense culture of $70 \mathrm{~cm}$ 


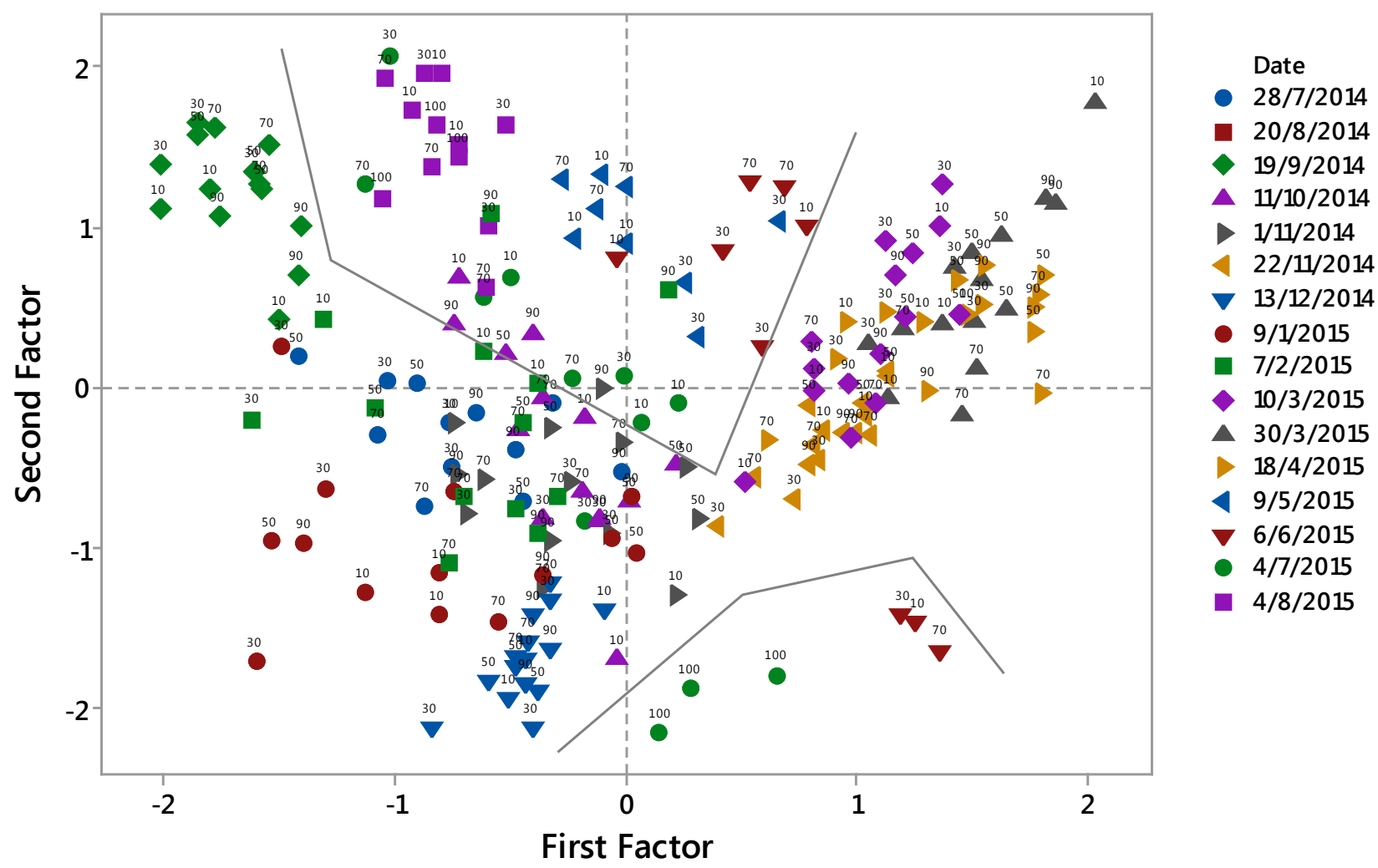

Figure 10. Ordination plot of the variable sample scores, showing the distances between the socks in both sampling periods (July 2014-August 2015). The two polygons enclose the samples belonging to the second period of the study.

distance. The less dense culture in the second sampling period comes along with the reference site. In the first sampling period, the densities of 30 and $50 \mathrm{~cm}$ distance are not clearly distinguished between each other but still, they have different characteristics from the 70 and $90 \mathrm{~cm}$ distances.

Figure 11 shows the position of depth points in the various sampling periods. Depth determines variation of ammonium and total inorganic nitrogen, indicating enrichment in the bottom layer, while chlorophyll $\alpha$ and phosphate concentration correlate well at the upper layer of the water body ( 1 and $5 \mathrm{~m}$ depth).

TRIX index incorporates nutrients as the driving forces of eutrophication, chlorophyll $\alpha$ as the biological response and deviation of dissolved oxygen saturation as the environmental disturbance factor. Eutrophication index (EI), derived from oligotrophic Greek coastal waters [9] is formed by nutrients and chlorophyll $\alpha$ concentration. TRIX values ranged from 0.02 to 4.16 , with a mean value of 1.64, while EI index ranged from 0.08 to 12.9, with a mean value of 3.05 . The results were classified in five trophic quality ranges, for TRIX, high $(<1.6)$, good (1.6 - 2.8), moderate (2.8 - 4), poor (4 - 5.3) and bad (>5.3) and for EI, high $(<0.04)$, good $(0.04-0.38)$, moderate $(0.38-0.85)$, poor $(0.85-1.51)$ and bad (>1.51), given a quality score from 1 to 5 , respectively. For comparison reasons, the trophic range was the same applied for Greek coastal waters [9] [16].

Figure 12 presents the ordination plot of nutrients, dissolved oxygen, total $\mathrm{N}$, $\mathrm{N}: \mathrm{P}, \mathrm{Chl} \alpha$, along with TRIX eutrophication index entered as a supplementary 


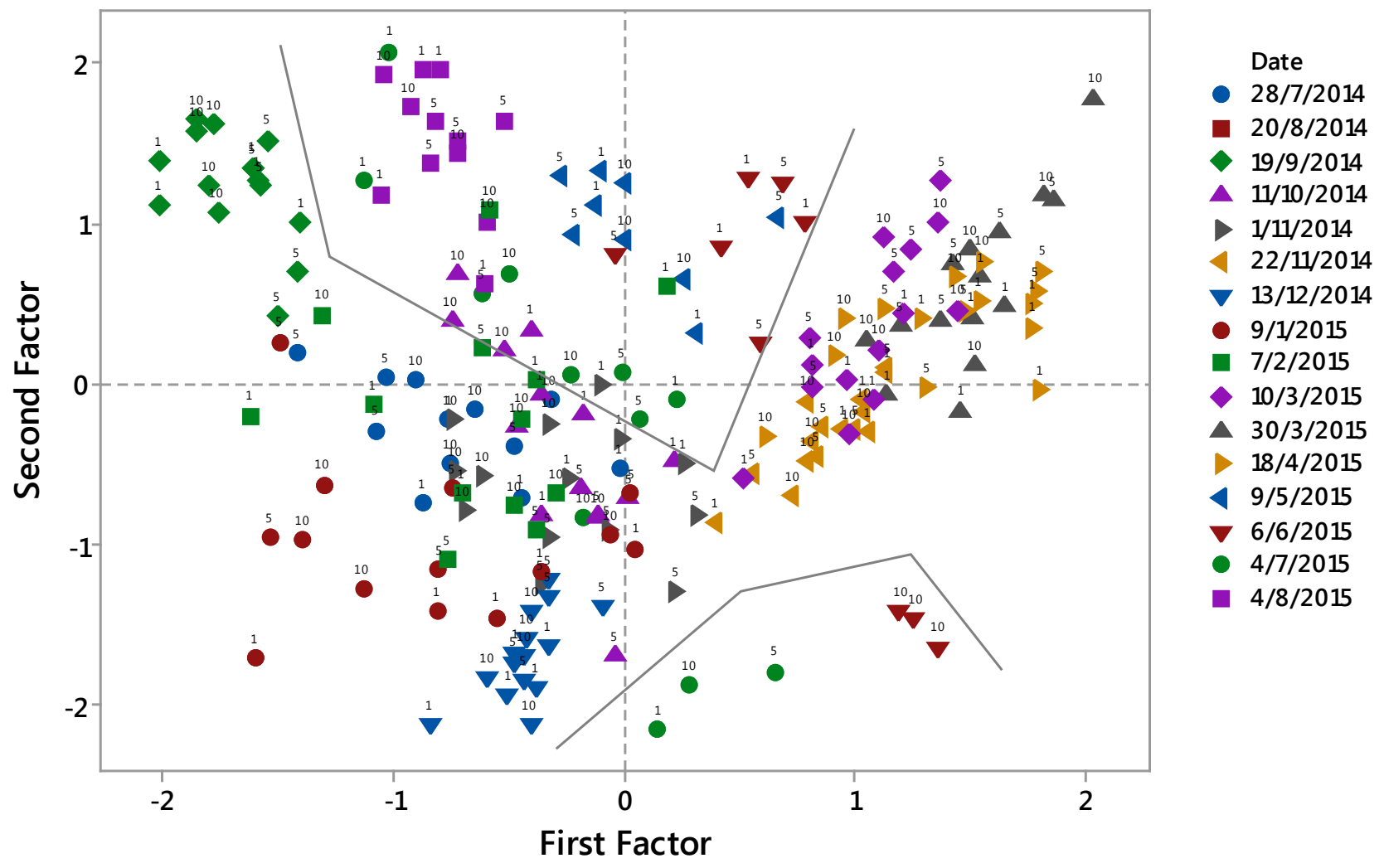

Figure 11. Ordination plot of the variable sample scores, showing the distribution of depth in the mussel culture in both sampling periods (July 2014-August 2015). The two polygons enclose the samples belonging to the second period of the study.

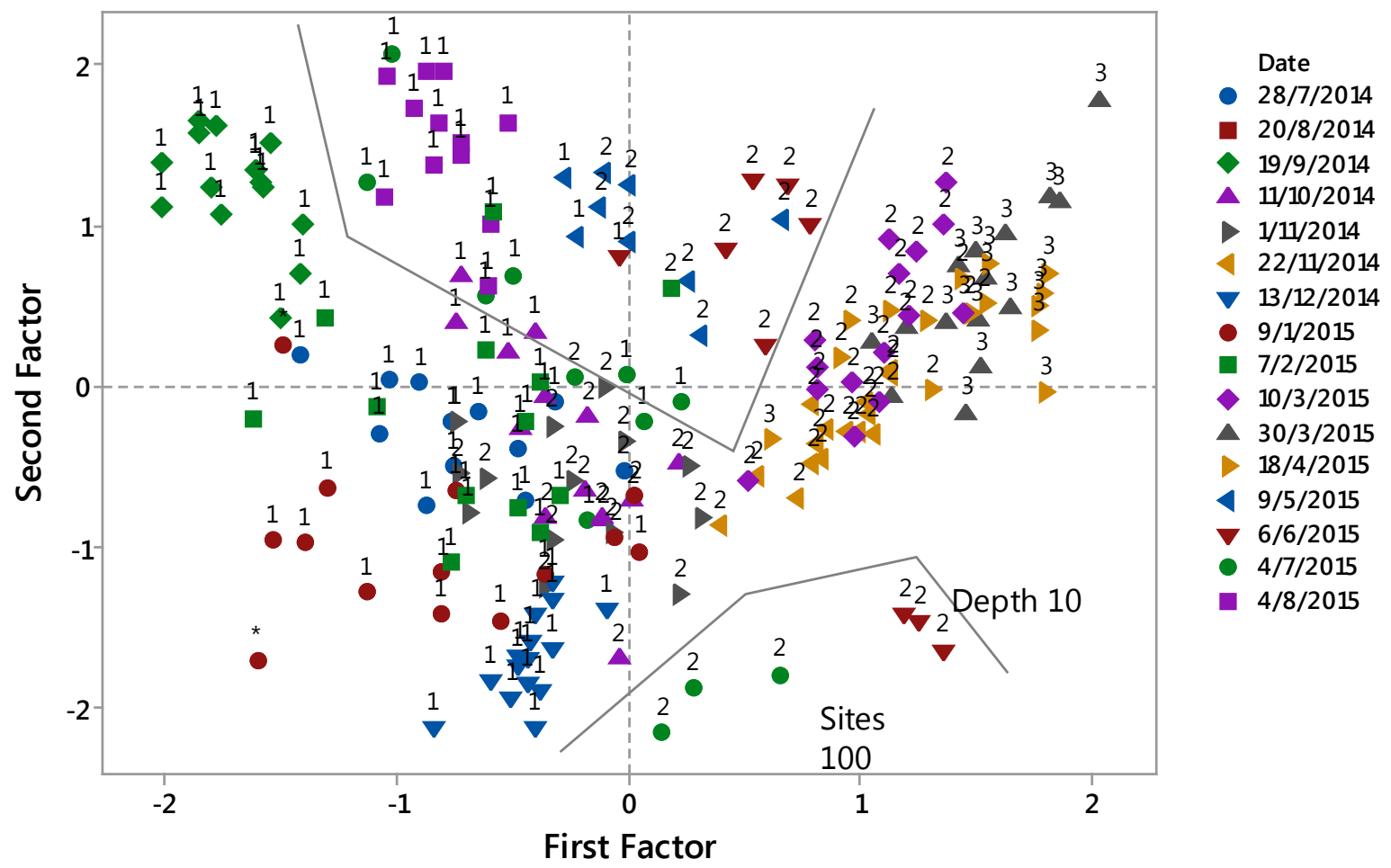

Figure 12. PCA biplot of sampling sites as arrayed by the TRIX classification index (quality scores from 1 - 5). The two polygons enclose the samples belonging to the second period of the study. 


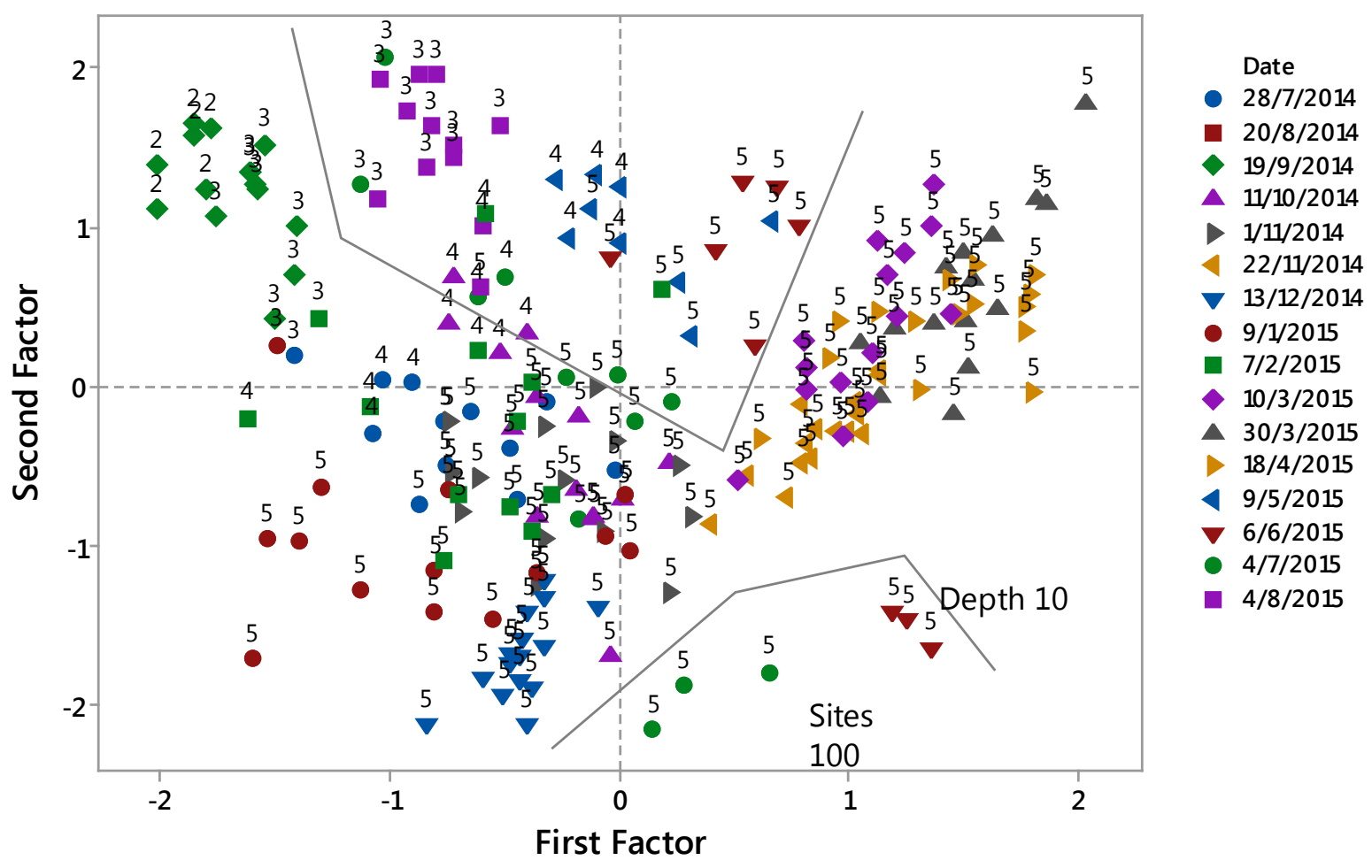

Figure 13. PCA biplot of sampling sites as arrayed by the EI classification index (quality values from 1 - 5). The two polygons enclose the samples belonging to the second period of the study.

quality value. The dense culture ( $30 \mathrm{~cm}$ distance) is distinguished (at the bottom right) from the $70 \mathrm{~cm}$ (upper part), classified in the middle (score 2) eutrophic scale. However, an unclear pattern (upper right part) of the classification of the four densities in the first sampling period is presented.

Figure 13 shows the PCA ordination plot of nutrients, dissolved oxygen, total $\mathrm{N}, \mathrm{N}: \mathrm{P}, \mathrm{Chla}$ and EI eutrophication index entered as a supplementary quality value. The application of this index, also confirms that the dense culture $(30 \mathrm{~cm}$ distance) is distinguished (at the bottom right) from the $70 \mathrm{~cm}$ (upper part). The classification range that was used, initially selected for oligotrophic waters [9] classifies the mussel's culture coastal environment in the worse (score 5) eutrophic scale.

\section{Discussion}

In this work, nutrient values were measured in an experimental long-line mussel culture in the area of Chalastra (NW Thessaloniki Gulf), where intensive mussel culture is an important economic activity. The study was conducted throughout a year (July 2014-August 2015). Two sampling periods can be identified, one assessing the parameters in all handlings (July 2014-April 2015) and the other assessing the parameters in selected handlings ( 30 and $70 \mathrm{~cm}$ between the socks). The study was an attempt to identify the different impacts of the culture density in the trophic conditions of the coastal waters of Thessaloniki's Gulf. The density of the culture was defined by the distance between the mussel socks. In the 
first study period, four mussel handlings of different sock distance were applied, 30, 50, 70 and $90 \mathrm{~cm}$, while in the second period (May-August 2015), two distances were selected, 30 and $70 \mathrm{~cm}$. Samples from a reference site outside the culture were also collected and analyzed.

Statistically important differences among the different handlings and the reference site were identified in the values of phosphates, nitrites and chlorophyll $\alpha$ as well as in the values of dissolved oxygen. On the contrary, nitrates and ammonium presented unimportant variation in the water column, inside the mussel culture and in the reference site, indicating nutrient mitigation from the mussels [6]. However, the fluctuation of the parameters had a different picture in the deeper layer, close to the bottom, where the prevailing ecological and environmental conditions need further evaluation. Phosphate concentrations increased with depth, suggesting enrichment from the bottom, probably due to resuspension and deliberation of phosphates from the sediments, but remained low in the sampling period. The lowest levels of phosphates were observed in December. Statistically significant differences among the handlings were observed for the phosphate values, indicating correlation between increased metabolic rate and phosphate enrichment [17] [18]. Depth was an important parameter for both phosphate and ammonium accumulation. The hydrodynamic circulation, investigated by Savvidis et al. [19] was characterized by low currents of average speed $<5 \mathrm{~cm} / \mathrm{s}$.

The presence of higher concentrations of ammonium and phosphate in the bottom layer of the culture has been also depicted in a monitoring study by Moriki et al. [20] inside the mussel farms at Chalastra area. In the same study, the correlation of elevated nitrite concentrations and low dissolved oxygen values has also been reported [20], along with low spatial and seasonal variation of nitrate.

The coastal waters of Thessaloniki's Gulf are affected by the estuaries of three major rivers, Axios, Loudias, Aliakmon as well as municipal, agricultural and industrial effluents from the metropolitan area of Thessaloniki. The nutrient status of the Gulf is constantly under monitoring from the local authorities, in the context of the European Directives, Water FD 2000/60/EC and Marine Strategy FD 2008/56/EC [21] [22]. According to HCMR [23] low dissolved oxygen values along with elevated nutrient levels and low values of current velocities and therefore water circulation have an impact to the eutrophic status of the area, with the contribution of the bivalve cultures in the NW of the Gulf. In this work, it was observed that the mussel culture has a low impact on nitrate and silicate values, while severe oxygen depletion along with elevated nitrite and ammonium values were observed in the bottom layer of the mussel culture. The density of the culture plays an important role in the accumulation of ammonium and nitrites, as observed in the second period of study (May to August 2015).

Multivariate statistical analysis was applied on the data set of both sampling periods, that included seven physicochemical parameters, measured at four sock 
distances (mussel density) in three vertical points of the water column during the two periods (July 2014-April 2015) and later on (May to August 2015) in two sock distances, corresponding to less dense and dense culture and was a valuable tool in identifying the variation scheme of the measured parameters. The positions of the variables on the PCA axes revealed the correlation of phosphate with chlorophyll $\alpha$ along with nitrate and nitrite, indicating the higher primary productivity and nutrients correlation, while ammonium concentrations played an important role in the variation of total dissolved inorganic nitrogen. Therefore, the driving forces for eutrophication are mainly phosphate, nitrate and nitrite as revealed by the PCA. High ammonium concentrations are accumulated in the mussel culture waters, especially in the deeper layer, close to the bottom. The distinction of different impacts of the mussel density in the eutrophication status was complicated in the first sampling period, when four mussel densities were investigated. However, data analysis, allowed the observation of the seasonal variation of the eutrophication parameters inside the mussel culture, during the mussel life cycle, from reproduction to growth and harvest. Chlorophyll $\alpha$ is an important environmental parameter that represents the phytoplankton biomass both as a eutrophication variable and as a measure of food availability in the mussel's culture complicated micro-environment. Low chlorophyll $\alpha$ values may have a negative impact in the development of eutrophication and therefore a positive impact in environmental quality, but reflect low food levels to support mussel growth in the culture. PCA revealed higher chlorophyll $\alpha$ values in the reference station, outside the culture, but the identification of the balanced relationship between chlorophyll $\alpha$ and mussel growth needs to be investigated.

Two eutrophication indices, TRIX and EI were used as a supplementary quality value for the classification of the sampling sites at the different mussel densities. Both indices were sensitive in identifying differences seasonally and spatially. However TRIX is a better environmental quality indicator, since clearly showed differences among the two selected mussel densities, 30 and $70 \mathrm{~cm}$ distance between the socks, in the period May-August 2015.

Nutrients, chlorophyll $\alpha$ and dissolved oxygen values were used as environmental quality indicators in the coastal waters of Thessaloniki's Gulf, inside and outside an experimental long-line of mussels in suspension. The parameters were undertaken multivariate statistical analysis in order to identify the implication of the culture in the trophic status of the coastal waters. PCA depicted the variation that is influenced by the mussel's density.

\section{Conclusions}

The investigation of nutrient variability in a long-line of suspended mussel culture of different densities showed clear differences between the dense $(30 \mathrm{~cm}$ distance of the socks) and the less dense culture (70 cm distance of the socks), especially in the bottom layer, while the TRIX and EI eutrophication indicators proved in a confirmatory matter the overall prevailing conditions on a seasonal 
basis.

The mussel density had implications on water quality, while food availability in terms of chlorophyll $\alpha$ was seriously affected compared to the reference station.

\section{Acknowledgements}

This research was partially funded by the operational programme "Fisheries 2007-2013".

\section{References}

[1] Galinou-Mitsoudi, S., Savvidis, Y. and Moriki, A. (2013) Mussel Culture in Greece, Fifty Years of Experience and Future Perspectives. 3rd Hellenic Congress in Technology of Animal Production, Zootechnia 2013, Thessaloniki, February 2013 (in Greek).

[2] Chamberlain, J. (2002) Modelling the Environmental Impacts of Suspended Mussel Farming. Ph.D Thesis, Napier University, Edinburg.

[3] Galimany, E., Ramon, M. and Ibarrola, I. (2011) Feeding Behavior of the Mussel Mytilus galloprovincialis (L.) in a Mediterranean Estuary: A Field Study. Aquaculture, 314, 236-243. https://doi.org/10.1016/j.aquaculture.2011.01.035

[4] Broekhoven Van, W., Troost, K., Jansen, H. and Smaal, A. (2014) Nutrient Regeneration by Mussel Mytilus edulis Spat Assemblages in a Microtidal System, Journal of Sea Research, 88, 36-46. https://doi.org/10.1016/j.seares.2013.12.007

[5] Mesnage, V., Ogier, S., Bally, G., Disnar, J.R., Lottier, N., Dedieu, K., Rabaille, C. and Copard, Y. (2007) Nutrient Dynamics at the Sediment Water Interface in a Mediterranean Lagoon (Thau, France): Influence of Biodeposition by Shellfish Farming Activities. Marine Environmental Research, 63, 257-277. https://doi.org/10.1016/j.marenvres.2006.10.001

[6] Petersen, J.K., Hassler, B., Timmermann, K., Nielsen, P., Torring, D.B., Larsen, M.M. and Holmer, M. (2014) Mussels as a Tool for Mitigation of Nutrients in the Marine Environment. Marine Pollution Bulletin, 82, 137-143. https://doi.org/10.1016/j.marpolbul.2014.03.006

[7] Devlin, M., Painting, S. and Best, M. (2007) Setting Nutrient Thresholds to Support an Ecological Assessment Based on Nutrient Enrichment, Potential Primary Production and Undesirable Disturbance. Marine Pollution Bulletin, 55, 65-73. https://doi.org/10.1016/j.marpolbul.2006.08.030

[8] Pettine, M., Casentini, B., Faza, S., Giovanardi, F. and Pagnotta, R. (2007) A Revisitation of TRIX for Trophic Status Assessment in the Light of the European Water Framework Directive: Application to Italian Coastal Waters. Marine Pollution Bulletin, 54, 1413-1426. https://doi.org/10.1016/j.marpolbul.2007.05.013

[9] Primpas, I., Tsirtsis, G., Karydis, M. and Kokkoris, G.D., (2010) Principal Component Analysis: Development of a Multivariate Index for Assessing Eutrophication According to the European Water Framework Directive. Ecological Indicators, 10, 178-183. https://doi.org/10.1016/j.ecolind.2009.04.007

[10] Vollenweider, R.A., Giovanardi, F., Montanari, G. and Rinaldi, A. (1998) Characterization of the Trophic Conditions of Marine Coastal Waters with Special Reference to the NW Adriatic Sea: Proposal for a Trophic Scale, Turbidity and Generalized Water Quality Index. Environmetrics, 9, 329-357. https://doi.org/10.1002/(SICI)1099-095X(199805/06)9:3<329::AID-ENV308>3.0.C 
$\underline{0 ; 2-9}$

[11] Giles, H., Pilditch, C.A. and Bell, D.G. (2006) Sedimentation from Mussel (Perna Canaliculus) Culture in the Firth of Thames, New Zealand: Impacts on Sediment Oxygen and Nutrient Fluxes. Aquaculture, 261, 125-140.

https://doi.org/10.1016/j.aquaculture.2006.06.048

[12] Knefelkamp, B., Carstens, K. and Wiltshire, K.H., (2007) Comparison of Different Filter Types on Chlorophyll-A Retention and Nutrient Measurements. Journal of Experimental Marine Biology and Ecology, 345, 61-70. https://doi.org/10.1016/j.jembe.2007.01.008

[13] Parsons, R., Maita, Y. and Lalli, M. (1984) A Manual of Chemical and Biological Methods for Seawater Analysis. Pergamon Press, Oxford, 173.

[14] Strickland, J.D.H. and Parsons, T.R. (1972) A Practical Handbook of Seawater Analysis. Journal of the Fisheries Research Board of Canada, 167, 361.

[15] Solorzano, L. (1969) Determination of Ammonia in Natural Waters by the Phenolhypochlorite Method. Limnology and Oceanography, 14, 799-801.

[16] Pavlidou, A., Simboura, N., Rousselaki, E., Tsapakis, M., Pagou, K., Drakopoulou, P., Assimakopoulou, G., Kontoyiannis, H. and Panayotidis, P. (2015) Methods of Eutrophication Assessment in the Context of Water Framework Directive: Examples from the Eastern Mediterranean Coastal Areas. Continental Shelf Research, 108, 156-168. https://doi.org/10.1016/j.csr.2015.05.013

[17] Saraiva, S., van der Meer, J., Kooijman, S.A.L.M. and Sousa, T. (2011) Modelling Feeding Processes in Bivalves: A Mechanistic Approach. Ecological Modelling, 222, 514-523. https://doi.org/10.1016/j.ecolmodel.2010.09.031

[18] Irisarri, J., Fernandez-Reiriz, M.J., Robinson, S.M.C., Cranford, P.J. and Labarta, U. (2013) Absorption Efficiency of Mussels Mytilus edulis and Mytilus galloprovincialis Cultured under Integrated Multi-Trophic Aquaculture Conditions in the Bay of Fundy (Canada) and Ria Ares-Betanzos (Spain). Aquaculture, 388-391, 182-192. https://doi.org/10.1016/j.aquaculture.2013.01.034

[19] Savvidis, Y., Antoniou, A., Stoilas, V.O. and Galinou-Mitsoudi, S. (2015) Hydrodynamics in Longline Mussel Culture Layouts. Proceedings of the Twelfth International Conference on the Mediterranean Coastal Environment, MeDCoast Varna, 06-10 October 2015.

[20] Moriki, A., Galinou-Mitsoudi, S., Petridis D., Kosti D., Savvidis, Y., Dimitriadis, X., Koutitas, C.H. and Alvanou, L. (2008) Environmental Impacts of Intensive Mussel Culture in the Coastal Waters of the Gulf of Thessaloniki (N. Greece). Fresenius Environmental Bulletin, 17, 1945-1955.

[21] European Commision (2000) Directive 2000/60/EC. A Framework for Community Actions in the Field of Water Policy. Official Journal of the European Communities, L327(1) 22.12.2000.

[22] European Commision (2008) Directive 2008/56/EC. A Framework for Community Actions in the Field of Marine Environmental Policy (Marine Strategy Framework Directive). Official Journal of the European Communities, L164(19) 25.06.2008

[23] HCMR (2001) Scientific Report on the Management of Mussel Production Zones in Thessaloniki and Thermaikos Gulfs. HCMR, Attiki, 147 (in Greek). 